Research papers

\title{
Oceanography at coastal scales: Introduction to the special issue on results from the EU FP7 FIELD_AC project
}

\author{
Agustín Sánchez-Arcilla ${ }^{\mathrm{a}, \mathrm{b}, *}$, Judith Wolf $^{\mathrm{c}}$, Jaak Monbaliu ${ }^{\mathrm{d}}$ \\ a Laboratori d'Enginyeria Marítima (LIM/UPC), Universitat Politècnica de Catalunya (UPC). Jordi Girona, 1-3, Ed. D1, 08031 Barcelona, Spain \\ ${ }^{\mathrm{b}}$ Centre Internacional d'Investigació dels Recursos Costaners (CIIRC). Jordi Girona, 1-3, Ed. D1, 08034 Barcelona, Spain \\ ${ }^{c}$ National Oceanography Centre, Joseph Proudman building, 6 Brownlow Street, Liverpool, UK \\ ${ }^{\mathrm{d}}$ Hydraulics Laboratory, KU Leuven, Kasteelpark Arenberg 40, Heverlee, Belgium
}

\section{A R T I C L E I N F O}

\section{Article history:}

Received 30 July 2013

Received in revised form

16 January 2014

Accepted 24 January 2014

\section{Keywords:}

Coastal oceanography

Domain boundaries

Interactions and coupling

High resolution modelling

Waves and currents

Land discharge

\begin{abstract}
A B S T R A C T
The high-resolution and coupled forecasting of wind, waves and currents, in restricted coastal domains, offer a number of important challenges; these limit the quality of predictions, in the present state-of-theart. This paper presents the main results obtained for such coastal domains, with reference to a variety of modelling suites and observing networks for: a) Liverpool Bay; b) German Bight; c) Gulf of Venice; and d) the Catalan coast. All of these areas are restricted domains, where boundary effects play a significant role in the resulting inner dynamics. This contribution addresses also the themes of the other papers in this Special Issue, ranging from observations to simulations. Emphasis is placed upon the physics controlling such restricted areas. The text deals also with the transfer to end-users and other interested parties, since the requirements on resolution, accuracy and robustness must be linked to their applications. Finally, some remarks are included on the way forward for coastal oceanography and the synergetic combination of in-situ and remote measurements, with high-resolution 3D simulations.
\end{abstract}

(c) 2014 Elsevier Ltd. All rights reserved.

\section{Introduction}

High-resolution meteo-oceanographic modelling is required to solve coastal scale oceanographic processes, where the local scale variability in orography and bathymetry (wind jets, diffraction, etc) produces spatial gradients, not always well captured by these models; this results in errors well in excess of those found for open sea conditions. The FIELD_AC project (Fluxes, Interactions and Environment at the Land-Ocean Boundary. Downscaling, Assimilation and Coupling), funded by the European Union FP7 Space Programme (2010-2012), aimed to provide and improve operational services for coastal areas and to generate added value for shelf and regional scale predictions, from GMES Marine Core Services. The Catalan coast in the North Western Mediterranean, the German Bight in the North Sea, Liverpool Bay in the Irish sea and the Gulf of Venice in the North Adriatic Sea have been used as case studies of coastal zones, with different physical processes and user needs.

Each of these coastal areas had an array of instrumentation deployed for several years and some enhancement of the previously-existing systems, carried out during the project. Nested

\footnotetext{
* Corresponding author. Tel.: +34 934016468 .

E-mail addresses: agustin.arcilla@upc.edu (A. Sánchez-Arcilla), jaw@noc.ac.uk (J. Wolf), jaak.monbaliu@bwk.kuleuven.be (J. Monbaliu).
}

modelling suites for the four contrasting environments were developed and compared, looking for: generic advances, such as the benefits of structured versus unstructured grids; and the added value of local data assimilation. The physical conditions range from micro- to macro-tidal and from being subjected to small to large storm surges. Wave conditions range from mild to severe and the degree of coastal irregularity shows also wide variability. In all the cases considered in FIELD_AC, the oceanographic domain can be considered as being semi-enclosed. Hence, the focus is upon the improvement of coastal predictions, through model down-scaling and more sophisticated model coupling, including land-ocean and atmospheric-ocean boundaries.

The coupling and nesting can be considered, in general, for: wind with waves; wind with currents; waves with currents or for a combination of wind, waves and currents. The waves have been noted to enhance the currents through the wave-induced mass fluxes and the excess momentum fluxes; through the gradients of radiation stresses, they modify also the mean water level. In contrast, the waves reduce the currents through increased bed shear stresses and may have an effect on air-sea momentum transfer.

Following, opposing or shear currents may spread out or focus the wave energy fluxes, resulting in modifications to wave height, period and direction. These wave-current interactions have been at the core of the Project, for macro-tidal conditions, where such an interaction is expected and, similarly, for micro-tidal conditions, 
where some current intensification events occur, for example off the Catalan coast. Some velocities of the order of $1 \mathrm{~ms}^{-1}$, the order of magnitude larger than the conventionally accepted currents, have been identified as significantly modifying the wave features.

The analysis has continued with the quest for the best strategy to include the continental discharge as a part of the land boundary condition. Likewise, how the frequency and accuracy of the offshore boundary condition, from regional operational models (within the MyOcean project), may affect the quality of the results obtained. Coastal domains, where the effect of this land boundary condition plays a key role, can be schematized in 2DH, 2DV or 3D approaches. Because of saltier water intrusion in near-bed layers and freshwater stratification near the surface layer, which is controlled also by wind, there is a requirement for 3D simulations and analyses. This need can be illustrated also by the intermittent stratification of the water column that has been observed in measurements and simulations, as a function of the freshwater discharge (on a short time-scale of hours to days) or solar radiation (on a medium-term time-scale, of days to months). We have observed also the difficulties in measuring salinity in turbid coastal environments and in determining sharp gradients, induced typically by coastal zone boundaries and transitions.

Such observations have led to the "ultimate" question of how best to combine models and local observations for robust coastal predictions, at the same time developing an insight into the underlying coastal oceanographic processes. This is the main hypothesis addressed by this Special Issue and summarised in this introductory paper. Towards this objective we have analysed different measurement networks and a number of numerical (wind/wave/current) models, with diverse coupling and nesting strategies. The modelling skill has been assessed in terms of bulk parameters; also, in terms of more local, physically-defined parameters, including metrics for displacement phase and amplitude of the various signals considered. Such an assessment has included also local assimilation since, in coastal domains the large variety of time and space scales involved (particularly the shorter ones), requires supplementing satellite images with in-situ observations. Satellite images can provide only a limited improvement, due to the rapid variability and sharp gradients mentioned above. Pointwise or in-situ measurements can contribute only locally to the improvement of results; this is due to the short time interval between observed information and information travel time, through the computational domain. As a consequence, observations will only have a transient effect in the simulations.

Following the above concepts, this introductory paper reviews the modelling tools and observational systems for the (4) case studies considered in the Project (Section 2). How the results obtained address users requirements is considered in Section 3. Finally, the performance limits of simulations and observations are considered, in terms of physical processes and the needs of coastal stake holders (Section 4). The text ends with some discussion on the future of coastal oceanography, acknowledging that "errors" grow as we get closer to the shore and this requires a combination of improved physical models - incorporating the non-linear processes typical of the near shore, such as those associated to wave breaking - / high-resolution in-situ observations /- capable of resolving the important gradients found near the coast due, e.g., to topo-bathymetric features - and remote images commensurate with the time/space scales present near the land-sea border.

\section{Models and observing systems for the study areas}

The four study sites, in which the methodology of the FIELD_AC project was applied, are Liverpool Bay, the German Bight, the Gulf of Venice and the Catalan coast. The first two locations are on the

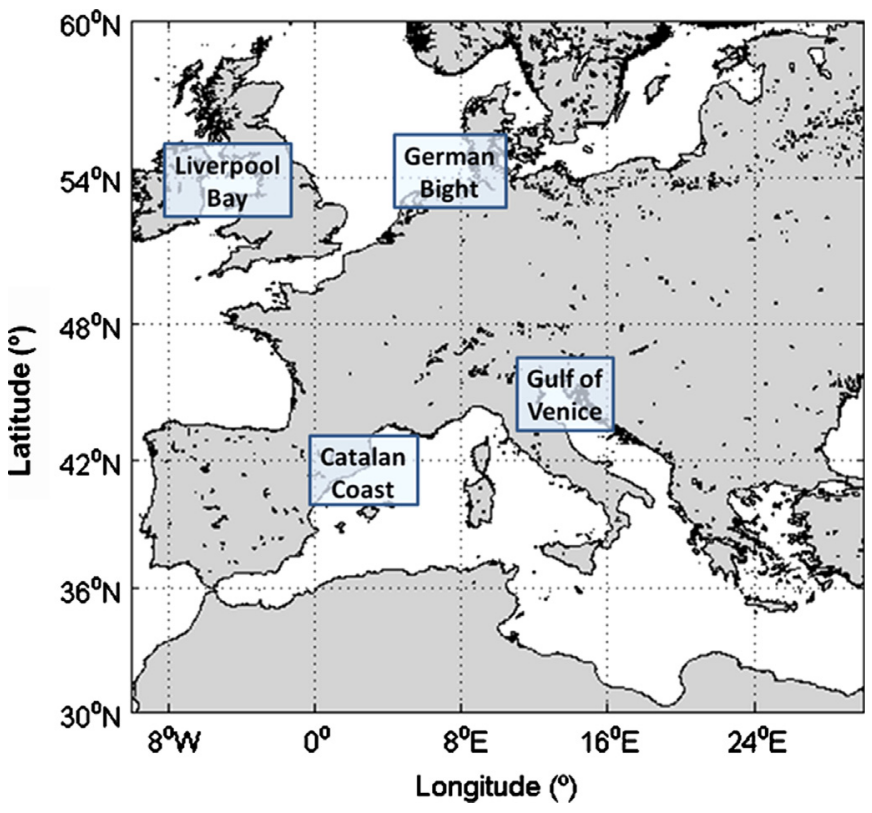

Fig. 1. Overview map of the four study site locations considered in the FIELD_AC project.

North-West European continental shelf, with moderate to large tides; the latter two are in the Mediterranean Sea, with low tidal ranges. Each site is in a coastal area affected by freshwater run-off, but experiencing different coastal management problems. The locations are shown in Fig. 1. A brief overview of their characteristics, together with the models and observing systems applied to each, are presented below. All the local models were embedded in the MyOcean regional forecast/analysis systems, for the NorthWest European Shelf and the Mediterranean.

Combining data with models, using data assimilation, enables an objective analysis of the environmental state which allows decisions based on "objectively" simulated (numerical) results supported by observations; this pre-supposes an improvement with respect to more qualitative environmental assessments, where assumptions sometimes lack the basis of an objective evaluation; this is due, among other reasons, to the limited resolution of coastal "details" in conventional oceanographic simulation.

\subsection{Liverpool Bay}

Liverpool Bay is a semi-enclosed shallow sea area $(<40 \mathrm{~m}$ deep), with a macro-tidal range (up to $10 \mathrm{~m}$ ) situated in the eastern Irish Sea, with extensive intertidal areas. It is a Region Of Freshwater Influence (ROFI), in which the runoff from the Rivers Mersey, Dee, Ribble and Conwy has a strong influence. It is somewhat sheltered from the prevailing south-westerly winds, but can be affected by winter storms. North-westerly winds generate fetch-limited waves, of up to $5 \mathrm{~m}$ in height. Coastal management issues include coastal flooding, erosion and water quality, as well as navigation for the Port of Liverpool.

The Liverpool Bay Coastal Observatory (2002-2012) was used to provide much of the observational data used in the project; these were supplemented by some additional observations made specifically for the FIELD_AC project. The Proudman Oceanographic Laboratory Coastal Ocean Modelling System, coupled with a wave model and the European Regional Seas Ecosystem Model (POLCOMS-WAM-ERSEM), were used; these were in addition to the FVCOM (Finite Volume Coastal Ocean Model) unstructured model, for the hydrodynamics, waves and ecosystem modelling. A nested model system was used, downscaling from a $12 \mathrm{~km}$ 
regional model (NW European continental shelf), via a $1.8 \mathrm{~km}$ Irish Sea model, to the Liverpool Bay coupled model system on a $180 \mathrm{~m}$ model grid. A calibrated conceptual rainfall/runoff model was developed by KU Leuven, specifically for the project. Daily river runoff data were available from the Environment Agency. A novel aspect of the modelling for FIELD_AC was to implement the WRF atmospheric model, at a local scale.

\subsection{German Bight}

The German Bight is a semi-enclosed sea with a moderate tidal range. The area lies in the south-eastern corner of the North Sea and the bathymetry is characterised by the extensive Wadden Sea, off the Friesian Coast, together with the estuaries of the Ems, Weser and Elbe rivers. The tidal range reaches $3.5 \mathrm{~m}$ in the mouth of the Elbe River (i.e. meso-tidal). The waters of the German Bight are relatively well mixed, by the strong tidal currents. The Wadden Sea is a narrow tidal water body located between the Ems river mouth in the west, the Jade Channel in the east, a chain of barrier islands in the north, and the German coast in the south. The narrow tidal inlets act as perforations in the shoreline, through which the North Sea water moves in and out; they are dynamically the most active part of the Wadden Sea, linking the processes on the intertidal flats to the external forcing from the North Sea. The inlets have an important role as waterways, with intense naval traffic; their vulnerability to sedimentation is a key issue. Surface waves in the German Bight are generated mainly by wind from northerly to westerly directions. Winds from northerly directions have a very long fetch. For westerly winds, the fetch is short and the waves generated are smaller and shorter in wavelength. Swell from the Atlantic enters the Bight mainly from the north-west: during storms, the significant wave height can reach more than $8 \mathrm{~m}$.

Observational capabilities in the German Bight have been established by the Coastal Observing System for Northern and Arctic Seas (COSYNA), which is a combination of in-situ observations, remote sensing and numerical modelling, developing a synoptic view of the southern North Sea. The main modellingplatform used in COSYNA is the General Estuarine Transport Model (GETM). This nested modelling system consists of three model configurations: a coarse-resolution (about $5 \mathrm{~km}$ ) North Sea-Baltic Sea outer model; a fine resolution (about $0.9 \mathrm{~km}$ ) inner model, covering the German Bight; and a very fine-resolution (about $200 \mathrm{~m}$ ) model for the Wadden Sea region, resolving the barrier islands and the tidal flats.

\subsection{Gulf of Venice}

The Adriatic Sea is a micro-tidal basin (with a tidal range of up to around $1.1 \mathrm{~m}$ and with tidal currents of up to $0.1 \mathrm{~ms}^{-1}$ ), with occasional storm surge events (of up to $1 \mathrm{~m}$ ), which can give rise to severe flooding in the city of Venice. The Gulf of Venice is the shallow northern sector of the Adriatic Sea which, in turn, is a semi-enclosed sub-basin of the north-eastern Mediterranean Sea. The Gulf of Venice is characterised by gentle bed slopes and relatively shallow depths, reaching maximum values up to $80 \mathrm{~m}$ in the south. The dominant wind regime includes the northeasterly Bora and the southeasterly Sirocco, blowing along the main axis of the basin. The wave climate reveals an annual mean significant wave height of around $1 \mathrm{~m}$, although Bora and Sirocco storms are responsible for local wave heights of up to $5 \mathrm{~m}$. The Po River is the largest river discharging in the basin, contributing to more than $70 \%$ of the total runoff, with an average water discharge of about $1500 \mathrm{~m}^{3} \mathrm{~s}^{-1}$. About 50 other rivers (some seasonal) contribute also to the freshwater runoff into the Adriatic. Such inputs represent a challenge to representative hydrological modelling, especially in the shallow northern part. Here, the correct modelling of the 3-D structure of river inputs (freshwater, sediment load, and tracers) is critical. The exchanges between the lagoon and the sea require such a 3D resolution and for some analysis the consideration of cohesive sediments.

Measurements of wind, sea level pressure, temperature, currents and waves have been collected at the ISMAR-CNR Acqua Alta Oceanographic platform, over many years. The Coupled OceanAtmosphere-Wave-Sediment Transport (COAWST) modelling system, which includes a 2-way coupled ROMS-SWAN model (ROMS is the Regional Ocean Model System), was implemented in the Adriatic; this is based upon two different curvilinear orthogonal computational grids. The coarse grid (with an uniform horizontal spacing of $2 \mathrm{~km}$, with 20 vertical sigma-levels) covers the Adriatic Sea, with a fine-resolution $(0.5 \mathrm{~km})$ grid in the Gulf of Venice.

\subsection{Catalan coast}

The Catalan coast is characterised by a micro-tidal environment, with a narrow continental shelf, bordering the deep Balearic basin of the Mediterranean. Here, the slope dynamics, dominated by a quasi-permanent slope current with meanders and eddies, can affect the outer part of the shelf. The atmospheric flow field over the Catalan coastal region is dominated by northerly and westerly winds during winter, but by southerly and easterly winds during spring. Offshore-directed winds can carry cold and dry air some hundreds of kilometres offshore, over the adjacent Mediterranean Sea. The effect of the mountainous terrain can mean a significant disturbance of winds coming from the north and west, leading to spatial variability of winds in the nearshore zone. Waves originate mainly from the east and south, with an annual mean significant wave height of around $0.8 \mathrm{~m}$ and with a maximum recorded wave height lying close to $6 \mathrm{~m}$. The annual rainfall of $400-600 \mathrm{~mm}$ is not particularly high, but the instantaneous rainfall can be intense and irregular. Some $50 \%$ the annual precipitation can fall within 2-3 days. Likewise, within 30-60 min, one quarter of the total annual precipitation can be recorded; this causes flash floods to be discharged into the ocean, via the rivers Llobregat and Besòs, as well as Combined Sewer Overflows, which can be locally important to nearshore water quality.

Some dedicated field campaigns were carried out during the FIELD_AC project, as well as making use of data from the existing XIOM network of wave buoys and current metres. Several model setups were used, including a series of nested ROMS-SWAN coupled models, as well as implementation of a commercial unstructured grid of the MIKE suite of models. A calibrated conceptual rainfall/urban runoff model was developed by KU Leuven, for the project. This study area was used also for a comparative modelling study, through adoption of all of the various modelling systems.

\section{The spin-off company and stakeholder interactions.}

The transfer of operational oceanography products, to end-users, suffers from limited resolution, accuracy and (even) reliability. Such limitations have led to a certain mistrust experienced by many potential "users". Within this research project, a number of workshops have been organised, with recipients of oceanographic predictions, in Venice, Hamburg, Liverpool and Barcelona. The vast majority of end-users were utilising, in a partial manner (i.e. without "exhausting" all possible applications), the meteorological predictions; some specific users accessed either the wave or current fields. Very seldom were users (mainly related to the offshore and renewable energy industry) applying both hydrodynamic fields; relatively few were aware of the potential for integrating all of these predictions, particularly if the final objective was assessing "fluxes" 
of water, sediment, nutrients or pollutants. Most users could identify precisely the prediction horizon (i.e. the maximum time limit for which predictions are offered). However, they were aware of the inconveniences of a 3-day horizon, which is clearly inappropriate when received on a Friday, to plan for the next week of operations.

In order to overcome some of these limitations, the two private companies in the FIELD_AC Consortium were commissioned to interact with the users, increase their knowledge about the potential of present operational oceanography. Likewise, showing how the advances developed in FIELD_AC could benefit their coastal activities and associated risks. The systematic underprediction of wave periods, where the relative error exceeds that of wave height, provides a good example to explain why the majority of the users were content to receive only the wave height. Another factor could be the relatively "unknown" asymmetric stratification in tidal regions. As a result, included in this issue are two contributions addressing: (i) such a wave period underprediction; and (ii) how tides produce asymmetric-strained stratification, as an example of the transfer from research, to coastal applications.

Within the project, the limits of coastal operational predictions have been analysed by incorporating Beach/Harbour Authorities and Offshore Groups, into the receiving group of users. With coastal resolutions extending down to $50 \mathrm{~m}$ (for beach or harbour applications) and prediction horizons extending to 5 days (for offshore applications), contacts were established with: fisheries; aquaculture farms; renewable energy companies; and construction companies. This approach has highlighted the importance of oceanographic predictions for coastal activities, but also: (a) the need to make explicit the uncertainty levels; and (b) to advance towards a certification system, that "qualifies" the accuracy of the simulations.

Such interaction, between users and stakeholders, has underlined the importance of visualisation tools, which had to be developed and customised within the project; this has taken place, together with a more efficient access to the site specific databases, comprising observations and simulations for each of the cases studied. An increase in the number of contracts (normally, service level agreements) has permitted the consolidation of the small spin-off company, launched at the beginning of the project for this purpose. The spreading of concepts such as baroclinic fields or residual currents, by the users, provides a further indication that which demonstrates how a planned transfer may assist in enhancing the dissemination of operational oceanography products.

\section{Some results from the study areas}

The wide variety of conditions in coastal domains implies an even larger range of phenomena that lead to complex modelling and observational results. In the papers included here, highresolution modelling and the problems of overly decreasing the mesh size are considered. Analyses have been undertaken on winds, waves and currents. Commencing with the meteo-drivers, the sensitivity of high-resolution meteorological models has been investigated, in response to any apparently minor change in the input information derived from global models (Bertotti et al., this issue). In the paper cited, the authors discuss the performance of two global meteorological models together, with the connected high-resolution models for the Mediterranean Sea. The latter is a particularly difficult area in which to predict wind conditions and, therefore, suitable for an high-resolution modelling and nesting (down-scaling) exercise. The quality of the meteo-model derived wind fields is assessed, on the basis of the quality of the wave fields obtained using the same wave model, in all cases.

The resulting wave fields have exemplified (Pallares et al., this issue) the challenge of predicting wave conditions in semienclosed domains, such as the Catalan coastal area in the western Mediterranean. The highly variable wind patterns obtained, with high-resolution nested meteorological models, permit the assessment of the spatial-temporal details in the resulting waves; this is particularly difficult for fetch- and duration-limited conditions, typical of this area. The importance of tuning the whitecapping dissipation term has been made apparent, when attempting to reduce the negative bias observed for standard settings of the wave models. The corresponding implications for other semienclosed domains are clear, if an increase in local errors for such cases is considered although this could be compensated for by adjusting the wave model.

The errors related to sharp gradients in the land-sea transition, due to differences in roughness or to the presence of mountain chains often present along Mediterranean coast, is another of the elements which help to explain the local discrepancies between measurements and observations in coastal areas. The rate of growth in the wave generation models can be tuned also to the observed local growth, which was observed to be more rapid than reported in the literature (Alomar et al., this issue). This faster growth rate, which is also more rapid than that provided by the standard model settings, has been improved in simulations by increasing the frequency of the wind input (from 6 to $3 \mathrm{~h}$ ). This approach has permitted an improved assessment of peak wave heights and periods, during the storm conditions analysed.

Following a similar analytical approach, the effect of coastal gradients in the high-resolution models for shelf and coastal domains has been addressed. The impact of various high-resolution nested model sequences, using a coupled wave-current 3D baroclinic model, has been analysed for macro-tidal conditions in the Liverpool Bay area (Bricheno et al., this issue). The effect of boundary conditions, model coupling and internal drivers, may lead to differences in nearshore waves and currents, particularly for shallow sea fronts. There may appear also differences in the asymmetrically-strained flow stratification (Howarth et al., this issue). The associated turbulence and sediment transport patterns are affected also by such modelling strategies, as shown during a spring-neap tidal cycle for the Liverpool Bay area, considering discharges from the four main estuaries.

The effect of boundary conditions is critical for the limited area coastal domains. The dependence of the circulation on boundary conditions has been assessed, in particular the land boundary condition, for the North Adriatic and the Catalan coast; these are two contrasting environments of the Western Mediterranean. The North Adriatic coast results demonstrate the controlling effect of local winds and the secondary role played by tides and baroclinic motions, with some exceptions for very specific and energetic events (Bolaños et al., this issue-a, this issue-b). Heat transfer has been shown to have strong impact, particularly during Bora events and when considering seasonal temperature variability. Most of the kinetic energy is found at diurnal and semi-diurnal frequencies, although the model winds do not show this signal. The windgenerated waves were found to be highly correlated with local winds, with limited quantifiable effects from the wave-current interactions.

As a result of the above analysis, the plume dynamics of the Po river have been investigated; this exerts a considerable influence on the Northern Adriatic Sea, with a daily average inflow up to $5500 \mathrm{~m}^{3} \mathrm{~s}^{-1}$. This study was the first model-based assessment of the inter-annual variability and dynamics of the Po river plume, complementing previous studies undertaken on this part of the Adriatic Sea. A multi-year period ( 8 years) has been analysed using 
the ROMS modelling system. The results have provided the basis for statistical analyses of the plume modes and paths, including a classification of the varying plume dynamics, in terms of spreading and evolution; these are found to be controlled mainly by riverine discharge and wind forcing (Falcieri et al., this issue). Analyses undertaken of this area have demonstrated the different performance of a commercial numerical model code, such as MIKE21/3, and a more scientifically-oriented code, such as COAWST.

In contrast, the freshwater inflow (the land boundary condition) to the Catalan coast is characterised typically by short-term flash flood events, also presenting important challenges for the modelling and observational studies. There is a strong correlation between the local wind and the modelled observed plume response (Liste et al., this issue), with a marked difference between low discharge conditions (corresponding to relatively calm periods) and the storm conditions (corresponding to the explosive growth of flash flood events). The land discharges associated with the latter case, which imply the "activation" of the two rivers from the Barcelona area (Besós and Llobregat), together with a nonnegligible amount of distributed (i.e. continental run-off reaching the sea along the full length of the shore-line border) continental discharge, have served to illustrate the importance of introducing such a 3D representation of land discharge into coastal oceanographic simulations.

The interactions between the different mechanisms of motion present in coastal areas has been studied also in some of the following papers, revealing some well-known and less-expected results. Wave-current interactions have been investigated, looking also at the implications of interacting fresh and salt water masses. In addition, the turbulence production and dissipation, that affects mainly the circulation field, have been considered.

The wave-current interaction analysis has been applied to the modulation of waves, by the macro-tidal conditions in Liverpool Bay (Bolaños et al., this issue-a, this issue-b). Tidal modulation affects the water depth and induces changes in wave height and wave period. Although wave effects are of second order, their consideration in the analysis improves the long-term modelled residual circulation profile. The changes in the major axis of the depth-averaged current are small, but incorporating a 3D radiation stress improves the minor axis current component. The riverine influence is also apparent, from the two-layer system observable in the residual currents.

The interaction between fresh and salt water masses, associated with the freshwater discharged into the coastal domain, has also been analysed. The emphasis has been placed upon the large gradients near the coast and the coexistence of dynamic models with a variety of time and space scales, which lead to large uncertainties. Even the capability to measure, (e.g.) salinity in turbid coastal waters, appears fraught with difficulties, especially in areas such as Liverpool Bay with strong tidal mixing and wellestablished horizontal and vertical density gradients. The appearance of a water column that stratifies intermittently has posed a significant challenge for measurements and modelling alike. The analysis of the longest time-series in the area has shown the lack of predominant periodicities and no consistent relationship to floods and storms; this permitted the conclusion that, on occasions, the river plume may remain closer to the shore than its morphodynamic signature

Finally, the turbulence field, resulting from and affecting all the other dynamic modes, has been analysed in terms of the turbulent kinetic energy dynamics. For this purpose, measurements from ADCPs and ADVs have been utilised, providing direct estimates of Reynold stresses (Souza and Betteridge. this issue). Turbulence production (almost routine) and turbulence dissipation (using a novel approach, based upon on the available measurements and structure function technique) have been calculated. This has permitted the comparison of turbulence production and dissipation, through the "structure function technique" applied to the ADCPs and direct estimation from the ADVs.

\section{Conclusions}

Coastal domains are characterised by strong interactions between meteo-oceanographic drivers, with bathymetry and boundary constraints. Coastal drivers can be considerably more energetic than their corresponding values in deeper waters. The water depth is limited and the wind shear stress, therefore, affects a higher proportion of the water column. Wind-generated waves extend to the sea bed much more easily: closer to the shore, the turbulence induced by wave-breaking dominates over other sources, with levels much higher than for offshore shelf waters.

Boundary constraints may produce current intensifications, wave focussing and, in general, a coexistence of multiple modes of motion, with sharp gradients. This characteristic can be illustrated by the strongly baroclinic circulation analysed for the domains studied in the Mediterranean, or by the sheared wavecurrent horizontal transects observed in Liverpool Bay or the German Bight. The heat transfer and funnelled winds have demonstrated their controlling capabilities for waves, currents and their mutually-interacting fields. This pattern has been illustrated for the Catalan coast by the Mestral or North-West wind jets and for the North Adriatic Sea with the well-known Bora or North-East wind.

Such rich structure and variability limit the value of point-wise observations, creating a challenge for even high-resolution numerical models. Nonetheless, it is in this coastal zone where most of the socio-economic activities take place. The request for highresolution predictions, sufficiently reliable to permit decisions to be taken, related to (e.g.) beach water quality or coastal safety, has been one of the main requirements for coastal users and stakeholders.

In FIELD_AC, the combination of in-situ and remote measurements, with high-resolution 3D simulations, have been addressed. Coastal-scale oceanography will gain significant new insight, when remotely-sensed images provide sufficient time-resolution to solve the short-duration coastal events (storms), with an average duration of often around $24 \mathrm{~h}$. The development of retrieval algorithms, where the land-ocean boundary does not degrade the image quality, will be also one of the key requirements. Regarding numerical models, turbulence closure remains one of the weakest links in the prediction sequence. Issues such as the coastal boundary layer, or the turbulence due to surface breaking waves and sea bed shear stresses under moving bed forms, need to be incorporated into the turbulence parameterizations.

The 3-way interaction between wind-wave-current fields needs to be included in the simulations, both for high tidal range environments and for the micro tidal conditions in the Mediterranean. In this latter case, the importance has been assessed of sharp gradients such as short duration low pressure centres, topographically steered wind jets, etc.; these contribute to degrade the quality of high-resolution simulated results.

Because of the above reasons, the synergetic combination of in-situ and remotely-sensed observations, with numerical model results, is considered to be a requirement to increase the reliability of forecasts: likewise, to establish some error bounds for the predictions obtained. Only with this quantified uncertainty can a 'build-up' of confidence be expected, together with an increased awareness of coastal oceanography products derived here, which will benefit also the production of Marine Core Services, dealing with deeper water dynamics. Such data will act as boundary 
conditions and drivers for the coastal oceanography predictions, lying much closer to the societal demands of coastal consumers.

\section{Acknowledgements}

The research leading to these results has received funding from the European Community's Seventh Framework Programme (FP7/ 2007-2013), under Grant Agreement no. 242284; this corresponds to the research project "Fluxes, Interactions and Environment at the Land-ocean boundary. Downscaling, Assimilation and Coupling (FIELD_AC)". It should be noted that this publication reflects the views only of the authors. The European Union cannot be held responsible for any use which may be made of the information contained therein.

\section{References}

Alomar, M., Sánchez-Arcilla, A., Bolaños, R., Sairouni, A. Wave growth and forecasting in variable, semien closed domains. Cont. Shelf Res., submitted for publication, this issue.
Bertotti, L., Cavaleri, L., Soret, A. Performance of global and high resolution nested meteorological models. Cont. Shelf Res., http://dx.doi.org/10.1016/j.csr.2013.12. 013, this issue.

Bricheno, L.M., Wolf, J., Brown, J. Impacts of high resolution modeld own- scaling in coastal regions. Cont. Shelf Res., http://dx.doi.org/10.1016/j.csr.2013.11.007, this issue.

Bolaños, R., Brown, J.M., Souza, A.J. Wave-current interactions in a tidal dominated estuary. Cont. Shelf Res., submitted for publication, this issue-a.

Bolaños, R., Tornfeldt Sørensen, J.V., Benetazzo, A., Carniel, S., Sclavo, M. Sources of currents in the northern Adriatic sea. Cont. Shelf Res., submitted for publication, this issue-b.

Falcieri, F., Carniel, S., Sclavo, M., Benetazzo, A., Russo, A. Po river plume variability and dynamics. Cont. Shelf Res., http://dx.doi.org/10.1016/j.csr.2013.11.001, this issue.

Howarth, M.J., Balfour, C.A., Player, R.J., Polton, J.A., Coastal density gradients near a macro-tidal estuary. Cont. Shelf Res., http://dx.doi.org/10.1016/j.csr.2013.11.016, this issue.

Liste, M., Grifoll, M., Monbaliu, J. Response to a fresh water delivery from a flash flood event: application to the Catalan shelf. Cont. Shelf Res., submitted for publication, this issue.

Pallares, E., Sánchez-Arcilla, A., Espino, M. Wave energy balance in the wave model SWAN for semi-enclosed domains. Application to the Catalan coast. Cont. Shelf Res., submitted for publication, this issue.

Souza, A.J., Betteridge, K.F.E. Estimates of the turbulent kinetic energy dissipation in shelf seas. Cont. Shelf Res., submitted for publication, this issue. 